\title{
MODEL PEMBELAJARAN TWILIGHT BALL THROWING ( Materi Perkembangan Islam pada Abad Pertengahan )
}

\author{
Komaruddin \\ Universitas Swadaya Gunung Jati Cirebon \\ el.qomar@yahoo.co.id
}

\begin{abstract}
Abstrak - Rendahnya mutu pendidikan di Indonesia disebabkan tidak maksimalnya peran guru dalam pembelajaran untuk mencapai tujuan perubahan perilaku kognitif, afektif dan psikomotor. Salah satu solusi dari masalah tersebut adalah model pembelajaran twilight ball throwing yang merupakan gabungan/kombinasi dari berbagai teknik pembelajaran aktif, kreatif, inovatif, dan menyenangkan. Tujuan pembelajaran menggambarkan proses dan hasil belajar yang diharapkan dicapai oleh peserta didik sesuai dengan kompetensi dasar. Adapun tujuan pembelajaran aspek Tarikh materi Perkembangan Islam pada Abad Pertengahan dengan model twilight ball throwing. Media pembelajaran adalah semua benda yang digunakan dalam proses belajar mengajar dalam rangka mempermudah atau memperjelas dalam penyampaian materi/bahan pelajaran. Kegiatan pembelajaran dimulai dengan mengklasifikasikan langkah-langkah pembelajaran. Langkah-Langkah pembelajaran aspek Tarikh materi Perkembangan Islam pada Abad Pertengahan . dibedakan menjadi dua, yaitu langkah-langkah yang dilakukan "guru, dan langkah pembelajaran peserta didik. Penskoran dilakukan dengan rentang nilai 1-10, menurut kualitas/kesungguhan perbuatan peserta didik sesuai dengan indicator. Selain observasi secara langsung, untuk mengukur sikap peserta didik dalam pembelajaran aspek Tarikh Materi perkembangan Islam pada Abad Pertengahan, juga dilakukan observasi secara tidak langsung dilakukan untuk mengetahui sikap peserta didik dalam kerja tim. Tes tertulis digunakan untuk mengukur ketercapaian indikator.
\end{abstract}

Kata Kunci : Pembelajaran, Twilight Ball Throwing.

\section{Pendahuluan}

Model pembelajaran twilight ball throwing merupakan gabungan/kombinasi dari berbagai teknik pembelajaran aktif, kreatif, inovatif, dan menyenangkan yang terdiri dari; pertama adalah melakukan kegiatan orientasi yang merupakan pemusatan perhatian peserta didik terhadap focus bahasan pada hari itu. Kedua, melakukan integrasi terarah ketiga teori dasar dasar twilight ball throwing pada waktu penanaman materi dengan cara mengaitkan materi awal (teori ausubel), mengacak kartu materi, membuat grouping di dalam kelas, menugaskan mereka untuk menyusun sendiri kartu materi agar lengkap (teori konstruktivisme), agar tugas individu dan kelompok berhasil maka diperlukan kerjasama tim (team working), komunikasi antar individu, dan kompetisi sebagai post test (cooperative learning).

Ketiga, membuat suasana belajar kelas yang nyaman dan santai, tanpa tekanan dan bebas ekspresi dengan cara melakuka.n permainan saling lempar bila kertas dan lempar bola plastik ke dalam keranjang. Bentuk permainan ini, terilhami oleh sebuah film bergenre fiksi, diangkat berdasarkan novel best seller lima jilid, dengan judul Twilight. Ada dua Scene dalam film tersebut yang menginspirasi terciptanya permainan dalam pembelajaran Pendidikan Agama Islam, khususnya aspek Tarikh. Sehingga berdasarkan latar belakang tersebut, maka nama model pembelajaran inipun diberi judul yang sama dengan judul film tersebut. Kendati metode yang diaplikasikan dalam pelaksanaan pembelajaran tersebut jauh dari kesan " Twilight" dari sisi bahasa.

\section{Tujuan Pembelajaran}

Tujuan pembelajaran menggambarkan proses dan hasil belajar yang diharapkan dicapai oleh peserta didik sesuai dengan kompetensi dasar. Adapun tujuan pembelajaran aspek Tarikh materi Perkembangan Islam pada Abad Pertengahan dengan model twilight ball throwing adalah:

a. Pada guru (pendidik) dapat merancang sistem pengajaran yang menarik, menyenangkan dan menggairahkan yang dapat berfokus pada hasil di mana peserta didik dapat menjelaskan perkembangan dunia Islam, ajaran Islam, ilmu 
pengetahuan dan kebudayaan pada abad pertengahan.

b. Para guru (pendidik) dapat menjadi rekan belajar, model, pembimbing, sekaligus fasilitator yang baik bagi peserta didik dan mampu meningkatkan kinerja pengajarannya dengan fokus hasil agar dapat mengambil manfaat dari sejarah perkembangan Islam pada abad pertengahan.

c. Mampu mengoptimalkan fungsi kerja otak peserta didik sehingga hasil pembelajaran peserta didik bertambah baik dengan mengembangkan delapan kecerdasan secara seimbang.

\section{Media Pembelajaran dan Sumber Belajar}

Media pembelajaran adalah semua benda yang digunakan dalam proses belajar mengajar dalam rangka mempermudah atau memperjelas dalam penyampaian materi/bahan pelajaran. Alat peraga yang digunakan dalam pembelajaran model twilight ball throwing pada aspek Tarikh mater Perkembangan Islam pada Abad Pertengahan adalah:

a. Globe

b. kertas HVS warna-warni

c. Bola Plastik

d. Spidol Warna

e. Karton

f. Keranjang Bola

g. TV \& VCD/CD Player

h. Notebook

i. Poster

j. White Board

Sumber belajar adalah segala sesuatu atau daya yang dapat dimanfaatkan oleh guru, baik secara terpisah maupun dalam bentuk gabungan, untuk kepentingan belajar mengajar dengan tujuan meningkatkan efektifitas dan efisiensi tujuan pembelajaran. Sumber belajar dapat berupa media cetak dan elektronik, nara sumber, serta lingkungan fisik, alam, sosial, dan budaya. Sumber belajaryang digunakan dalam pembelajaran aspek Tarikh pada materi Perkembangan Islam pada Abad Pertengahan dengan model "Twilight Ball Throwing" adalah:
a. Atlas
b. Internet
c. Buku Diktat Pendidikan Agama Islam
d. Ensiklopedia Islam
e. Majalah

\section{Kegiatan Pembelajaran}

Kegiatan pembelajaran dimulai dengan mengklasifikasikan langkah-langkah pembelajaran. Langkah-Langkah pembelajaran aspek Tarikh materi Perkembangan Islam pada Abad Pertengahan . dibedakan

menjadi dua, yaitu langkah-langkah yang dilakukan "guru, dan langkah pembelajaran peserta didik.

\section{a. Langkah Pembelajaran Guru}

Langkah pembelajaran yang dilakukan oleh guru, dilakukan dengan urutan:

1) Memahami Permendiknas No. 22 tentang standar Isi Mata Pelajaran, termasuk PAI.

2) Setelah mencermati $S K / K D$ yang tertuang pada Permen No. 22 tahun 2006, dilakukan pembuatan silabus dengan langkah:
a. Mengkaji Standar Kompetensi dan Kompetensi Dasar
b. Menyusun Indikator pencapaian kompetensi.
c. Mengindentifikasi materi pembelajaran.
d. Merancang Model Pembelajaran.
e. Merancang ]enis Penilaian.
f. F) Merencanakan alokasi waktu.
g. Menentukan sumber belajar.

3) menyusun RPP, dimana RPP disusun dengan langkah:
a. Mencantumkan indentitas RPP
b. Menuliskan tujuan pembelajaran
c. Menentukan materi pembelajaran
d. Menentukan metode pembelajaran
e. Menyusun langkah-langkah kegiatan pembelajaran
f. Menuliskan sumber belajar
g. Menyusun teknik penilaian.

\section{b. Langkah Pembelajaran Peserta didik}

1) Alokasi waktu $2 \times 45$ menit.

2) Tujuan Pembelajaran

3) Materi Pembelajaran

a. Peserta didik dapat menjelaskan perkembangan dunia Islam, ajaran Islam, ilmu pengetahuan, dan kebudayaan pada abad pertengahan.

b. Peserta didik dapat mengambil manfaat dari sejarah perkembangan Islam pada Abad Pertengahan.

c. Perkembangan ajaran Islam, ilmu pengetahuan, dan perkembangan kebudayaan Islam pada abad Pertengahan.

d. Hikmah mempelajari perkembangan Islam pada abad pertengahan.

4) Metode Pembelajaran Team work, games, diskusi, ceramah sebagai clues, dan tugas kelompok.

5) Kegiatan Pembelajaran. Menggambarkan skrenario pembelajaran dan uraian materi.

\section{c. Aturan Main}


1) Satu kelas dibagi menjadi empat kelompok. Setiap kelompok menyiapkan yel, nama dan indentitas kelompok, juga memilih pemimpin bagi kelompok.

2) Menyiapkan kerta manila sebagai papan bintang, tempat menulis nama setiap kelompok dan mengakumulasi perolehan jumlah award berupa bintan. Tempat dekat white board. Gunakan selama satu semester untuk satu mata pelajaran (PAI). Berikan penghargaan untuk kelompok yang berhasil mengumpulkan bintang paling banyak. Hadiah diberikan kepada tim dengan bintang terbanyak di akhir semester.

3) Pemberian bintang dilakukan pada saat:

a. Setiap kelompok mendemonstrasikan yel-nya

b. Anggota kelompok mampu menjawab pertanyaan pembuka (Pre Test dan pertanyaan penutup (Post Test)

c. Menang atau berhasil melalui simulasi games permainan materi.

d. Melakukan tugas dengan baik. Tugas bisa dalamlbentuk tagihan, resume, kerja kelompok/ teamwork atau test.

e. Melakukan presentasi dengan baik.

f. Melakukan praktek (demonstrasi materi)

4) Bintang juga bisa berkurang apalagi:

a) Melanggar komitmen kelas

b) Anggota kelompok absen, sedangkan ketua dan anggota kelompoknya tidak mengetahui alasan ketidakhadiran salah satu anggota tersebut.

c) Melakukan kecurangan dalam setiap games.

5) Hadiah diberikan kepada perseorangan atau kelompok dalam bentuk bebaš.

6) Memutar music untuk mengiringi atau menandai pelajaran tertentu. Seperti saat presentasi musik yang digunakan musik Mozart, The Bond, Kenny G, Kintaro, dan lain-lain. Pada saat simulasi, musik yang digunakan pop, rap, dan lain-lain. Para peserta didik boleh membawa kaset sendiri atau request lagu kesukaannya. Pada saat pemberian tugas, music yang digunakan adalah music jazz, Kintaro, dan lain-lain.

7) Meminta kelas menyiapkan 4 orang atau beberapa orang sebagai asisten, untuk membantu kita menyiapkan pelajaran, untuk menempelkan sesuatu di papan, untuk menghapus white board, untuk mengambil atau membagikan tugas, untuk membantu guru tatkala melakukan simulasi.

\section{d. Kegiatan Awal}

1) Orientasi

Orientasi dilakukan untuk memusatkan perhatian peserta didik ada materi
Perkembangan Islam pada Abad Pertengahan. Orientasi dengan menunjukkan garnbargambar, peta-peta yang berkaitan dengan perkembangan Islam di Abad pertengahan.

2) Apersepsi

Apersepsi dilakukan untuk memberikan persepsi awal kepada peserta didik tentang materi yang akan diajarkan. Apersepsi dilakukan dengan mengajukan pertanyaan pancingan, misalnya: Apa yang kalian fikirkan jika ibu mengatakan Taj Mahal? Menurut kalian apa itu arsitektur Islam?

3) Motivasi

Motivasi dila.kukan untuk memberikan gambaran manfaat mempelajarai jejak sejarah umat Islam dan perkembangannya pada abad pertengahan, bagi kehidupan kita dan bagi masa depan perkembangan Islam sendiri.

\section{e. Kegiatan Inti}

Peserta didik menyimak penjelasan guru tentang perkembangan Islam pada abad pertengahan. Materi yang disampaikan guru meliputi:

1) Kerajaan Ottoman di Turki

Kerjaan Ottoman Turki didirikan dan diproklamasikan kemerdekaannya oleh Usman I (dari Bangsa Turki Usmani). Sekitar tahun 1300M. Sistem kerajaan Otokrat, Usman I sebagai raja I. Mengalami kemajuan pada masa SultanMuhammad II (1451-1481M), yang bergelar Al-Fatih (Sang Penakluk). Karena menyebarluaskan Islam di Benua Eropa melalui penaklukan Konstantinopel - Romawi Timur 1453 M. Mengalami masa keemasan pada masa Sultan Sulaeman I (1520-1566 M), bergelar Sulaeman Agung/ al Qonuni. Pada masanya, Ottoman menguasai tiga lautan; lautan hitam, laut merah, dan laut tengah.

2) Kerajaan Moghul di India

Kerajaan Moghul didirikan oleh Zahiruddin Muhammad Babut, keturunan Jengkhis Khan bangsa Mongol, $1526 \mathrm{M}$, berpusat di Delhi India. Setelah itu diperintah secara silih berganti oleh 15 orang raja (Sultan). mengalami puncak kejayaan dibawah pimpinan Akhbar Syah I (1556-1605 M), Syah Jihah (1627-1658 M) dan Aurangzeb/Alamgir I (1658-1707 M). sultan terakhir adalah sultan Bahadur Syah II (1837$1858 \mathrm{M})$.

3) Kerjaan Syafawi di Persia (Iran sekaran)

Islam mengusai Persia (Iran sekarang) tahun $641 \mathrm{M}$, semula mereka adalah pemeluk Zoroaster. Namun bangsa Mongol merebutnya abad $12 \mathrm{M}$ menguasainya selama 3 abad kemudian. Setelah itu

barulah muncul dinasti baru, ya.kni dinasti Syafawi. Pendirinya adalah Syah Ismail Syafawi (Ismail I) tahun 907 M di Tabriz. Mencapai puncak kejayaan di bawah pimpinan Syah Abbas 
(1585-1628 M). setelah itu selama pemerintahannya silih berganti sultan yang memerintah sebanyak 17 . Salah satu penyebab majunya bangsa Eropakini adalah berkat perkembangan Islam pada abad pertengahan melalui kerajaan Persia.

4) Perkembangan Ajaran Islam pada Abad Pertengahan

Beberapa Ulama yang hidup pada masa Pertengahan, diantaranya adalah:

a) Jalaludin Al Mahalli (Mesir - $791 \mathrm{H}$ ) dan Jalauiddin as Suyuthi (849-911 H), pengarang kitab Tafsir Jalalain.

b) Ibnu Katsir (Bosyra/300 M - Damaskus/ $1373 \mathrm{M})$ Pengarang kiab Tafsir Al Qur'anul ‘Adzhim.

c) Imam Nawawi (damaskus/1233 M - 1277 M) pengarang kitab Hadis Riyadus Shalihin.

5) Perkembangan Ilmu Pengetahuan pada Abad Pertengahan Beberapa cendikiawan yang hidup pada masa abad pertengahan, diantaranya adalah:

a) Ibnu Abi Usaibiah (menulis buku "Penyampai Infirmasi dalam Tingkatan Para Dokter")

b) Abu al-Fida dan al-Maqrizi terkenal sebagai penulis sejarah kedokteran

c) Abu Hasan Ali Nafis, kepala Rumah Sakit Cairo, penemu susunan dan peredaran darah dalam paru-paru manusia.

d) Nasiruddin at-Tusi, ahli observatorium

e) Abu Fajar Ath Thabari ahli matematika

4) Perkembangan Kebudyaan Islam pada Abad Pertengahan
a) Bidang Arsitektur
b) Bidang Kaligrafi
c) Bidang Sastra

Sastrawan muslim sufi yang terkenal pada abad pertengahan adalah Jalaluddin ar-Rumi (1207$1273 \mathrm{M})$.

\section{f. Kegiatan Akhir}

1) Peserta didik menjawab pertanyaan guru tentangmateri perkembangan Islam pada Abad pertengahan yang dijabarkan.

2) Mendengarkan petunjuk guru tentang aturan games yang akan dilakukan.

\section{g. Skenario Pembelajaran}

1) Mengucapkan salam kita masuk kelas dengan tampilan prima, segar dan ceria. Menyapa anak-anak, mengingatkan mereka (suggestology) bahwa "saya" berada di kelas yang tepat, karena saya guru yang hebat, mengajar di kelas yang hebat dengan peserta didik yang terhebat. Meminta kerjasama mereka karena menarik tidaknya pelajaran hari ini tergantung bagimana cara mereka merespons suasana kelas hari ini. Meminta mereka membaca Al-Fatihah sejenak.
2) Meminta asisten untuk membantu menempelkan karton di white board, membagikan kertas materi kepada masingmsing kelompok. Menyalakan music bord.

3) Pemberian bintang bagi kelompok yang paling semangat.

4) Sebelum menyampaikan materi, kita memberikan petunjuk tentang kegiatan apa saja yang akan kita lakukan hari itu, dan seberapa pentingnya materi itu bagi kehidupan kita. Pastikan agar anak-anak tidak melewatkannya.

5) Pembagian kertas materi kepada empat kelompok dengan isi materi yang berbeda. Kemudian meminta setiap pemimpin kelompok untuk mendiskusikan, mencatat, atau mentrasformasikan ini materi tersebut dengan alokasi waktu 1 menit, anggota lainnya mencatat.

6) Apabila waktu habis, kelompok bertukar kertas materi dengan kelompok lain, begitu selanjutnya, sampai empat kertas materi yang berbeda tersebut mendapat bagan yang rata. Seluruh kegiatan tersebut berlangsung totally empat menit.

7) Setelah itu ketas diambil oleh guru. Asisten membagikan kertas HVS warna-warni kepada seluruh peserta didik. Berikan waktu tambahan 1 menit kepada kelompok untuk berdiskusi ulang tentang isi keempat kertas materi yang telah didiktekan ketua kelompoknya tadi. Berikan petunjuk bahwa mereka semua harus mengingat dengan jelas seluruh pesan pendek dari kertas yang didiktekan tersebut.

8) Waktu habis peserta didik diminta untuk berdiri melingkar membentuk lingkaran kecil. Masing menghadap ke arah temannya sehingga yang terlihat hanya punggung temannya. Minta mereka untuk menuliskan namanya sendiri pada kertas HVS tadi di punggung temannya.

9) Kemudian, minta mereka menulis satu sampai tiga pertanyaan yang berkaitan clengan materi yang baru saja didiskusikan dengan teman kelompoknya tadi. Setelah itu minta mereka meremas kertasnya monjadi sebuah bola.

10) Berikan waktu 10 menit kepada peserta didik untuk saling melempar bola kertas tadi (saling timpuk). Ketika peluit berbunyi pastikan mereka mcmpunyai satu bola kertas, yang entah milik siapa yang sudah tentu bukan miliknya sendiri.

11) Minta setiap peserta didik membuka bola kertasnya, dan menjawabnya pcrtanyaan tersebut dengan menulis namanya dan kelompoknya. Minta beberapa peserta diclik untuk membacakannya di depan kelas. Biarkan peserta didik lain yang mengkoreksi kebenarannya jawaban temannya. 
12) Pemberian bintang kepada setiap anak dan asal kelompoknya yang menjawab benar.

13) Kemudian, sebelum pelajaran berakhir lakukan post test dalam bentuk games. Bagikan bola plastic seukuran bola kasti kepada setiap pescrta didik. Minta mereka menulis nama dan asal kelompoknya dengan spidol. Sementara guru mempersiapkan Notebook clan LCD untuk memberikan clue.

14) Munculkan abjad, atau angka......, lemparkan pertanyaan yang jawabannya adalah abjad atau angka tersebut. Minta mereka menjawabnya dengan cara memasukkan bola ke dalam keranjang bola yang telah disediakan sebelumnya.

15) Minta mereka tetap membentuk lingkaran, keranjang bola di tengah lingkaran. Yang bolanya masuk pertama kali yang berhak menjawab. Contoh: apabila cli layar kita munculkan abjad $\mathrm{T}$, kemudian kita lontarkan pertanyaan, bangunan di India yang merupakan peninggalan islam?....... jawabannya tentu saja Taj Mahal. (T untuk Taj Mahal). Begitu juga untuk angka yang menunjukkan tahun, dan seterusnya. Berikan bintang bagi peserta didik yang bisa menjawab pertanyaan dengan cepat dan betul.

16) Jelang waktu berakhir, sampaikan ucapan terima kasih kepada kelas karena kerjasama mereka hari itu. Lontarkan pujian bahwa kelas kompak, kelas hebat, dan kita berada di tempat yang tetap. Minta mereka menghargai diri sendiri dan usahanya dengan tepuk tangan dan yel penyemangat.

17) memberikan hadiah kepada kelompok yang meraih bintang paling banyak. Ucapkan salam, meminta asisten untuk membersihkan ruangan.

\section{h. Teknik Evaluasi}

teknik evaluasi pada model pembelajaran "twilight Ball Throwing" meliputi :

1) Observasi

Observasi digunakan sebagai alat penilaian untuk mengukur sikap peserta didik terhadap pembelajaran aspek Tarikh materi perkembangan Islam pada Abad Pertangahan dengan Model "Twilight Ball Throwing". Jenis observasi yang dipilih adalah observasi secara langsung dan tidak langsung. Pada observasi langsung, guru melakukan observasi terhadap gejala perilaku peserta didik dalam proses pembelajaran. Sedangkan observasi tidak langsung dilakukan oleh peserta didik selama melakukan interaksi kelompok.
Daftar penilaian sikap dengan teknik observasi langsung disusun sebagai berikut :

Tabel 1

Daftar penilaian sikap dengan teknik observasi langsung

\begin{tabular}{|l|l|l|l|}
\hline No & Nama & Indikator & Nilai \\
\hline 1 & & Ketepatan hadir & $1-10$ \\
& & dikelas & \\
& & Memperhatikan & \\
& & penjelasan guru & \\
& & Mengajukan & \\
& & pertanyaan/pendapa & \\
& t & \\
& & Ketepatan & \\
& & mengumpulkan & \\
& tugas & \\
& Kerapian & \\
& & mengerjakan tugas & \\
& & Kejujuran dalam & \\
& & mengerjakan tes & \\
& &
\end{tabular}

Penskoran dilakukan dengan rentang nilai 1-10, menurut kualitas/kesungguhan perbuatan peserta didik sesuai dengan indicator. Selain observasi secara langsung, untuk mengukur sikap peserta didik dalam pembelajaran aspek Tarikh Materi perkembangan Islam pada Abad Pertengahan, juga dilakukan observasi secara tidak langsung dilakukan untuk mengetahui sikap peserta didik dalam kerja tim.

Table 2

Daftar penilaian sikap dengan teknik observasi tidak langsung

\begin{tabular}{|l|l|l|l|l|}
\hline No & \multirow{2}{*}{$\begin{array}{l}\text { Perilaku/sik } \\
\text { ap }\end{array}$} & \multicolumn{3}{|l|}{ Muncul/dilakukan } \\
\cline { 3 - 5 } & $\begin{array}{l}\text { selalu } \\
\text { Mau }\end{array}$ & $\begin{array}{l}\text { kad } \\
\text { ang } \\
\text { mengerjaka } \\
\text { n tugas tim }\end{array}$ & & $\begin{array}{l}\text { Tidak } \\
\text { perna } \\
\text { h }\end{array}$ \\
\hline 2 & $\begin{array}{l}\text { Aktif dalam } \\
\text { kegiatan tim }\end{array}$ & & & \\
\hline 3 & $\begin{array}{l}\text { Mau bekerja } \\
\text { secara tim } \\
\text { work }\end{array}$ & & & \\
\hline 4 & $\begin{array}{l}\text { Tidak } \\
\text { memaksaka } \\
\text { n kehendak }\end{array}$ & & & \\
\hline
\end{tabular}

\section{Skala likert}

Skala likert digunakan untuk mengukur minat peserta didik dalam mengikuti pembelajaran aspek Tarikh materi perkembangan Islam pada abad pertengahan pertengahan dengan model "Twilight Ball Throwing". Kuisioner nilai yang digunakan dalam penilaian minat sebagai berikut :

Tabel 3 


\section{Kuisioner minat peserta didik dalam mengikuti pembelajaran aspek tarikh Materi Perkembangan Islam pada Abad Pertengahan dengan model "Twilight Ball Throwing"}

\begin{tabular}{|c|c|}
\hline No & PERTANYAAN \\
\hline $\begin{array}{l}1 \\
2 \\
3 \\
4 \\
5 \\
6 \\
7 \\
8\end{array}$ & $\begin{array}{l}\text { Saya merasa rugi apabila terlambat } \\
\text { masuk kelas saat pembelajaran Tarikh } \\
\text { dimulai } \\
\text { Saya selalu menyiapkan pertanyaan } \\
\text { sebelum mengikuti pembelajaran aspek } \\
\text { Tarikh } \\
\text { Saya berusaha memperhatikan } \\
\text { keterangan guru dalam menyampaikan } \\
\text { materi aspek Tarikh } \\
\text { Saya berusaha mencatat keterangan } \\
\text { guru dalam pembelajaran materi Tarikh } \\
\text { Catatan materi tarikh saya terdapat } \\
\text { coretan-coretan tentang hal-hal yang } \\
\text { penting } \\
\text { Saya berusaha melengkapi catatan } \\
\text { materi tarikh apabila tertinggal } \\
\text { Saya berusaha mengulangi/belajar } \\
\text { materi PAI yang diajarkan oleh guru } \\
\text { Saya berusaha mengerjakan tugas } \\
\text { individu/teamwork tentang materi } \\
\text { tarikh secara sungguh-sungguh } \\
\text { Saya berusaha menyerahkan tugas PAI } \\
\text { tepat pada waktunya } \\
\text { Apabila memahami kesulitan saya } \\
\text { mendiskusikan materi tarikh dengan } \\
\text { sesame teman materi tarikh sangat } \\
\text { Saya merasa materian saya } \\
\text { bermanfaat dalam kehidupan say } \\
\text { sehari-hari individu/kelompok tentang } \\
\text { Tugas mendorong keberanian saya } \\
\text { tarikh mentaks dengan } \\
\text { untuk melakukan komunikasi } \\
\text { orang lain. }\end{array}$ \\
\hline
\end{tabular}

\section{Tes Tertulis}

Tes tertulis digunakan untuk mengukur ketercapaian indicator. Teknik yang digunakan adalah uraian, tes uraian adalah adalah alat penilaian yang menentukan peserta didik untuk mengingat, memahami, dan mengorganisasikan gagasannya hal-hal yang sudah dipelajari.

4. penilaian produk

Penilaian produk merupakan penilaian terhadap proses pemburuan dan kualitas produk/karya peserta didik. Penilaian produk digunakan dalam menilai hasil tugas individu, dengan format sebagai berikut :

Table 4

Daftar penilaian tugas individu

\begin{tabular}{|l|l|l|}
\hline No & Aspek & Skor \\
\hline 1 & Kesesuaian tugas & $1-20$ \\
2 & & \\
\hline
\end{tabular}

\begin{tabular}{|l|l|l|}
\hline 3 & Kreatifitas inovatifitas & \\
4 & tugas & \\
5 & Kerapian tugas & \\
& Organisasi tugas & \\
& Ketetapan \\
& mengumpulkan tugas & \\
\hline
\end{tabular}

Table 5

Daftar penilaian tugas kelompok

\begin{tabular}{|l|l|l|}
\hline No & Aspek & \multicolumn{2}{|c|}{ Skor } \\
\hline 1 & Ketetapan menyerahkan & $1-20$ \\
2 & tugas & \\
3 & Kerapian hasil laporan & \\
4 & Kesesuaian dengan & \\
5 & tugas & \\
& Kelengkapan tugas & \\
& Sistematika tugas & \\
\hline
\end{tabular}

\section{DAFTAR PUSTAKA}

[1] Borg, W. R. 1981. Applying Education Research: A Practice Guide for Teachers. New York: Longman.

[2] Darajat, Z. 1992. Ilmu Pendidikan Islam. Jakarta: Bumi Aksara.

[3] Doll, R. C. 1992. Curriculum Improvement: Decision Making and Process. Boston: Allyn \& Bacon, Inc.

[4] Fajar, Malik 1998. Meningkatkan Pemberdayaan Pendidikan di Indonesia. Majalah Dinamika No. 09 / Juli-Agustus 1998.

[5] Finch, C. R. and Crunkilton, J. R. 1979. Curriculum Development in Education Planning, Content, and Implementation. Boston: Allyn and Bacon, Inc.

[6] Gagne, R. M. and Briggs, L. J. 1974.

Principles of Instructional Design.

New York: Holt, Rinehart and

Winston.

[7] Hamalik, Oemar. 1990.

Evaluasi Kurikulum. Bandung:

Remaja Rosdakarya. 1990.

Kurikulum dan Pembelajaran.

Jakarta: Bumi Aksara.

[8] Hasan, S. Hamid 1988. Evaluasi

Kurikulum. Jakarta: Depdikbud,

Ditjen Dikti, P2LPTK.

[9] Ibrahim, R. dan Sudjana, Nana 1989.

Penelitian dan Penilaian Pendidikan.

Bandung: Sinar Baru.

[10] Moejiono dan Dimyat. 1993.

Strategi Belajar-Mengajar.

Jakarta: Depdikbud, Ditjen PT. 
[11] Nawawi. 1997. Kesenjangan Kurikulum PAI antara Rencana dan Penerapannya serta Sumbangan Kerjasama Pembinaannya dalam Mengatasi Kesenjangan Kurikulum (Tesis, tidak diterbitkan). Bandung: PPs IKIP.

[12] Rasyidin, W. 1988. Kemampuan Mengajar Dilihat dari Kemampuan Bidang Studi dan Penguasaan Proses Belajar-Mengajar. (Disertasi, tidak diterbitkan). Bandung: PPs IKIP.

[13] Sanusi, A. 1998. Pendidikan Alternatif. Bandung: Grafindo Media Pratama. 